\title{
Park 'n' Roll: Identifying and prioritizing locations for new bicycle parking in Quebec City, Canada
}

\author{
Marie-Pier Veillette \\ School of Urban Planning \\ McGill University \\ Suite 400, 815 Sherbrooke St. W. \\ Montréal, Québec, H3A 0C2 \\ Canada \\ Tel.: 514-398-4058 \\ Fax: 514-398-8376 \\ E-mail: marie-pier.veillette@mail.mcgill.ca \\ Emily Grisé \\ School of Urban Planning \\ McGill University \\ Suite 400, 815 Sherbrooke St. W. \\ Montréal, Québec, H3A 0C2 \\ Canada \\ Tel.: 514-398-4058 \\ Fax: 514-398-8376 \\ E-mail: emily.grise@mail.mcgill.ca \\ Ahmed El-Geneidy \\ School of Urban Planning \\ McGill University \\ Suite 400, 815 Sherbrooke St. W. \\ Montréal, Québec, H3A 0C2 \\ Canada \\ Tel.: 514-398-4058 \\ Fax: 514-398-8376 \\ E-mail: ahmed.elgeneidy@mcgill.ca
}

Paper submitted for the 2018 Transportation Research Board (TRB) Annual Meeting.

Word count: (5 figures, 5177 words)

For Citation Please use: Veillette, M., Grisé, E., \& El-Geneidy, A. (2018). Park ' $n$ ' Roll: Identifying and prioritizing locations for new bicycle parking in Quebec City, Canada. Paper presented the 97th Annual Meeting of the Transportation Research Board, Washington D.C., USA. 


\begin{abstract}
Promoting active modes of transportation, such as cycling, is an ongoing challenge faced by many cities around the world. Fostering a bicycle culture in an auto dominant region is riddled with challenges, but success has been achieved with investments in bicycle infrastructure, including bicycle parking. This study presents a new methodology to identify the optimal locations to install short-term (bicycle racks) and long-term (bicycle lockers or indoor locking facilities) bicycle parking using a GIS-based approach that considers multiple criteria. Using the City of Quebec, Canada, as a case study, our methodology considers multiple criteria related to the demand for bicycle parking, including the destinations of existing and potential cyclists and proximity to frequent bus service. A prioritization index is developed to identify the optimal locations for long-term and short-term bicycle parking. This is followed by a recommendation of the number of bicycle parking spaces required to meet existing and potential demand. This paper aims to provide practitioners with an easy-to-use method to aid in the planning of new bicycle parking infrastructure, which is designed to be flexible and adaptable to other contexts.
\end{abstract}

Keywords: Bicycle parking demand; Secured bicycle parking; Spatial analysis; Multi-criteria analysis 


\section{INTRODUCTION}

2 A broad body of literature has explained the positive effects of the presence of bicycle 3 infrastructure, such as bicycle lanes, parking, showers, and availability of bicycle-sharing 4 system on cycling levels in a region (1-3). In the Netherlands, Denmark and Germany, 5 measures related to bicycle parking supply and security, as well as interventions aimed at 6 better integrating cycling with other modes, have promoted cycling as a safe and convenient 7 mode of transport, and thereby increased bicycle usage $(2 ; 4)$. Locating bicycle parking, 8 however, has received little attention in the cycling literature. The aim of this study is to 9 develop an easy-to-reproduce GIS-based method to identify and prioritize locations to add new short-term (bicycle racks) and long-term (bicycle lockers or indoor facilities) bicycle parking in Quebec City, Canada.

This paper seeks to answer three main research questions: 1) how can a region prioritize the installation of new short-term bicycle parking in order to meet the needs of existing and potential cyclists; 2) how can the same region locate long-term bicycle parking; 3) what are the quantities of long-term and short-term bicycle parking spaces needed to accommodate existing and potential demand? We define short-term bicycle parking as any type of free-standing rack, similar to those presently provided by the city of Quebec and many North American cities, and long-term bicycle parking as any bike storage, locker or shed with restricted access and typically provided for a fee, similar to what is present at major public transport stations in European cities. Our study builds on a previous method developed by Larsen, Patterson and El-Geneidy (5), who proposed the creation of a GIS-based prioritization index to identify high-priority grid cells to guide bicycle network improvements at a city-wide scale. The paper is divided in four sections. We will first provide an overview of the existing literature on bicycle parking, which will be followed by a brief description of our study area. The next section, the core of this paper, will be dedicated to describing our methodology and presenting our findings. Finally, we will discuss the implications and recommendations of our results.

\section{LITERATURE REVIEW}

The presence of end-of-trip facilities, such as bicycle parking and showers, has been identified as an important factor in increasing bicycle modal share for utilitarian purposes $(1$; $2 ; 6-8)$. However, the perceived risk of bicycle theft and vandalism can deter individuals from cycling $(9 ; 10)$. van Lierop, Grimsrud and El-Geneidy (11) studied the locations of stolen bicycles and found that $50 \%$ of reported stolen bicycles were locked in a fly-parking fashion. Fly-parking is a concept that refers to locking a bicycle to any type of street furniture that is not proper bicycle parking $(11 ; 12)$. Accordingly, providing cyclists with a sufficient supply of bicycle parking at destinations, especially in areas where the bicycle mode share is increasing, has the potential to reduce bicycle theft and subsequently encourage bicycle usage (9).

For optimal levels of security against bicycle theft, particularly for individuals parking their bike for long periods of time, demand and preference for bicycle parking that provides greater levels of security is rising. Long-term bicycle parking is typically referred to in the literature as a bicycle facility guarded by an individual or a facility which limits access through electronic keys (12). Bicycle lockers have also been added to the list of long-term bicycle parking as they are usually present near destinations, such as train stations (1). In Montreal, Canada, a Bicycle Theft Survey conducted in 2012 revealed that cyclists perceived bicycle lockers as more secure against theft compared to free-standing bicycle racks (11). 
The availability of long-term bicycle parking and showers at destinations was found to have a significant influence on bicycle usage (13). More specifically, Wardman, Tight and Page (7) presented evidence that the availability of outdoor bicycle parking at work increased the share of trips to work by bicycle from $5.8 \%$ to $6.3 \%$. However, the combination of both indoor bicycle parking, described as more secure than outdoor, and showers at work would increase bicycle mode share from $5.8 \%$ to $7.1 \%$.

The presence of bicycle parking near the public transit network can lead to a betterintegrated transportation system (1). In this respect, previous studies in the Netherlands have noted the key role of cycling as a means to access train stations, and thus highlighted the importance of providing bicycle spaces near stations $(10 ; 14)$. Van der Spek and Scheltema (15) reported, among other examples, the case of Zutphen Station, in the Netherlands, where a "guarded" bicycle parking facility was built in 2006 in proximity to the train station, and increased the number of train users who cycle to the station from $41 \%$ in 2004 to $58 \%$ in 2009. Similarly, the availability of short-term and long-term bicycle parking near train stations increased cyclist's satisfaction and bicycle usage for bike-and-ride purposes (14).

Krizek and Stonebraker (16) identified key challenges related to the integration of bicycle and transit use, and evaluated five potential ways of integrating bicycle with transit. For example, the Final Mile Initiative, implemented by Boulder County, is a program that supplies bicycle lockers and bicycle loans along their regional bus routes. The authors mentioned that the program aims to limit the number of bicycles aboard buses in order to improve the bus service by reducing the dwell time (16).

Bachand-Marleau, Larsen and El-Geneidy (17) highlighted that bicycles on buses (BOB) are the most common way to integrate these two modes together in North-American cities. The authors found that $60 \%$ of respondents in their study preferred taking their bicycle aboard transit. This preference can potentially be explained by either the absence of secure bicycle parking at stations or by an actual need of bringing a bicycle aboard a transit vehicle for access to their bicycle upon egress from the transit service. Despite the potential benefit of bringing bicycles aboard transit vehicles, longer dwell time associated with passengers bringing bicycles aboard buses has led to programs aimed at limiting the number of bicycles aboard buses (16). While these two studies provide conflicting views on the integration of bicycles and transit use, better long-and short-term bicycle parking at transit stations would be beneficial for the integration of these two modes.

Although recent studies used a GIS-based approach to plan for new bicycle lanes and bike-sharing stations, no study has developed a methodology to specifically identify the optimal locations to install long-term and short-term bicycle parking $(5 ; 18 ; 19)$. This study tries to fill this gap by using a multi-criteria GIS-based approach, which modifies and expands on a similar method developed by a previous study (5).

\section{STUDY AREA}

The City of Quebec is the second largest populated urban center in the province of Quebec, Canada with 531,902 inhabitants in 2016 (20). The study area is divided into five boroughs, for a total area of approximately $454 \mathrm{~km}^{2}(20)$. Similar to many North American cities, the construction of highways between 1960 and 1980 encouraged the localization of employment nodes and housing developments at the periphery of the inner city, which in turn contributed to the creation of a polycentric-structured city (21). Nowadays, the presence of highways, in addition to railways, rivers and territory steepness, are major barriers to the existing bicycle network expansion and consolidation (22).

In 2016, the City announced its Bicycle Vision to encourage a modal shift toward cycling by specifically improving the safety and connectivity of the bicycle network (22). 
1 Nine kilometers of new bicycle paths and 60 more bicycle parking racks were added in 2016 2 (23). Presently, the City of Quebec has around 424 kilometers of bicycle network and 480 3 short-term bicycle parking (bicycle racks) of either 3, 5, and 7 spaces each, for a total of 4 nearly 3,784 public bicycle parking spaces available for cyclists. The distribution of these 5 parking spaces is presented in Figure 1.
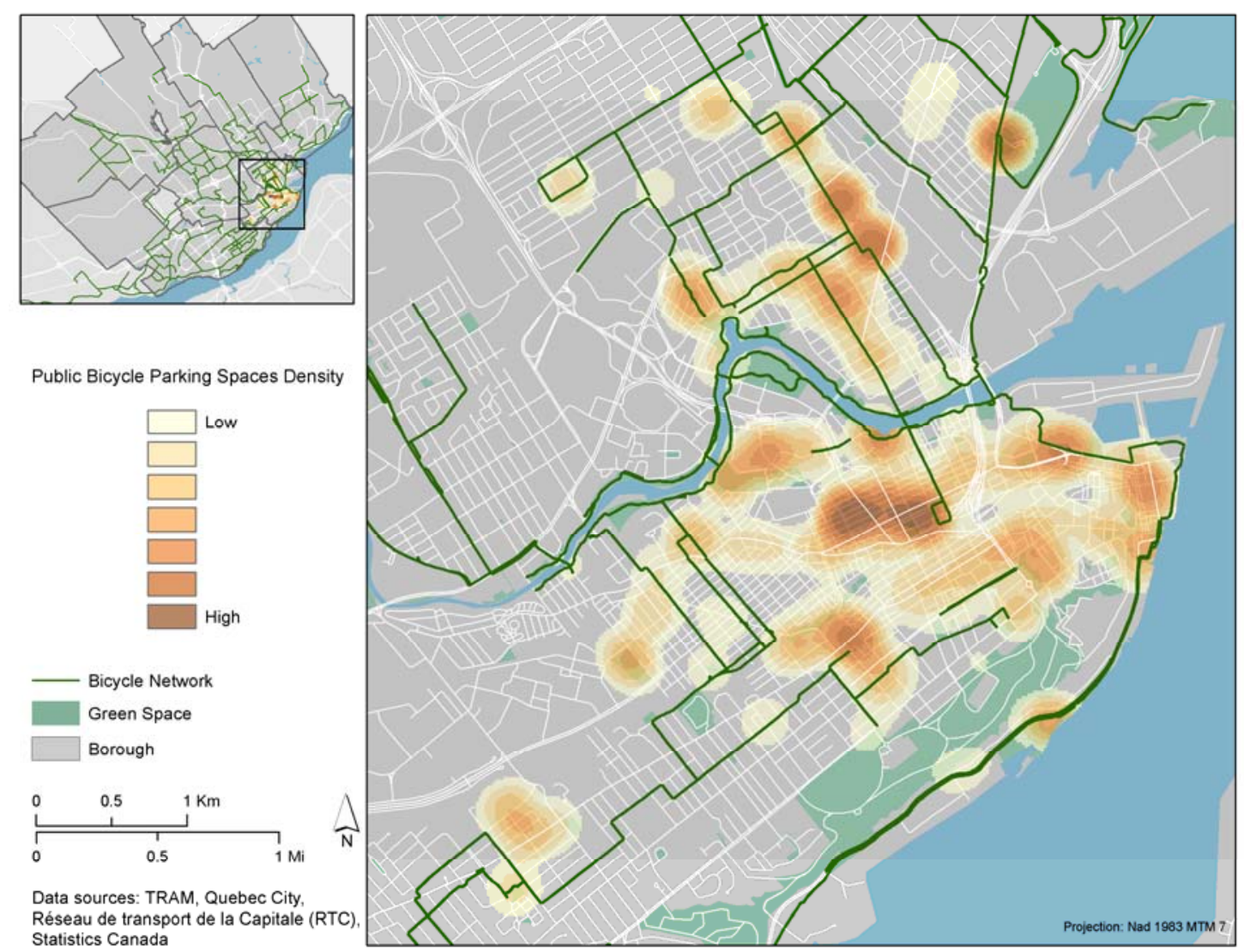

Public Bicycle Parking Spaces Density
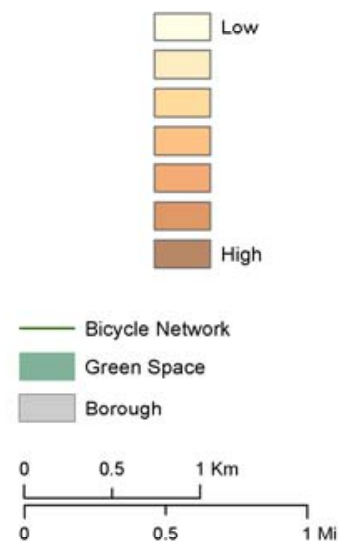

Data sources: TRAM, Quebec City, Réseau de transport de la Capitale (RTC) Statistics Canada

7 FIGURE 1 Location and density of municipal bicycle parking spaces in 2017.

\section{METHODOLOGY, DATA AND RESULTS}

Our method consists of a multi-criteria approach to prioritize the location of new long-term and short-term bicycle parking. A flow chart illustrating the main steps of our analysis is displayed in Figure 2. Using data of the destinations of existing and potential cyclists, as well as the proximity of the bicycle network to high frequency bus stops, we developed a priority index for locations with the highest need for new bicycle parking. A second priority index is then developed that identifies where long-term bicycle parking is needed among the locations identified in the previous step. Finally, the number of recommended bicycle parking spaces for these locations is calculated, taking into account the current supply of bicycle parking. We generate two priority maps, one for long-term and one for short-term bicycle parking needs in the region. The data employed in our analysis will be described in further detail in the following section. 


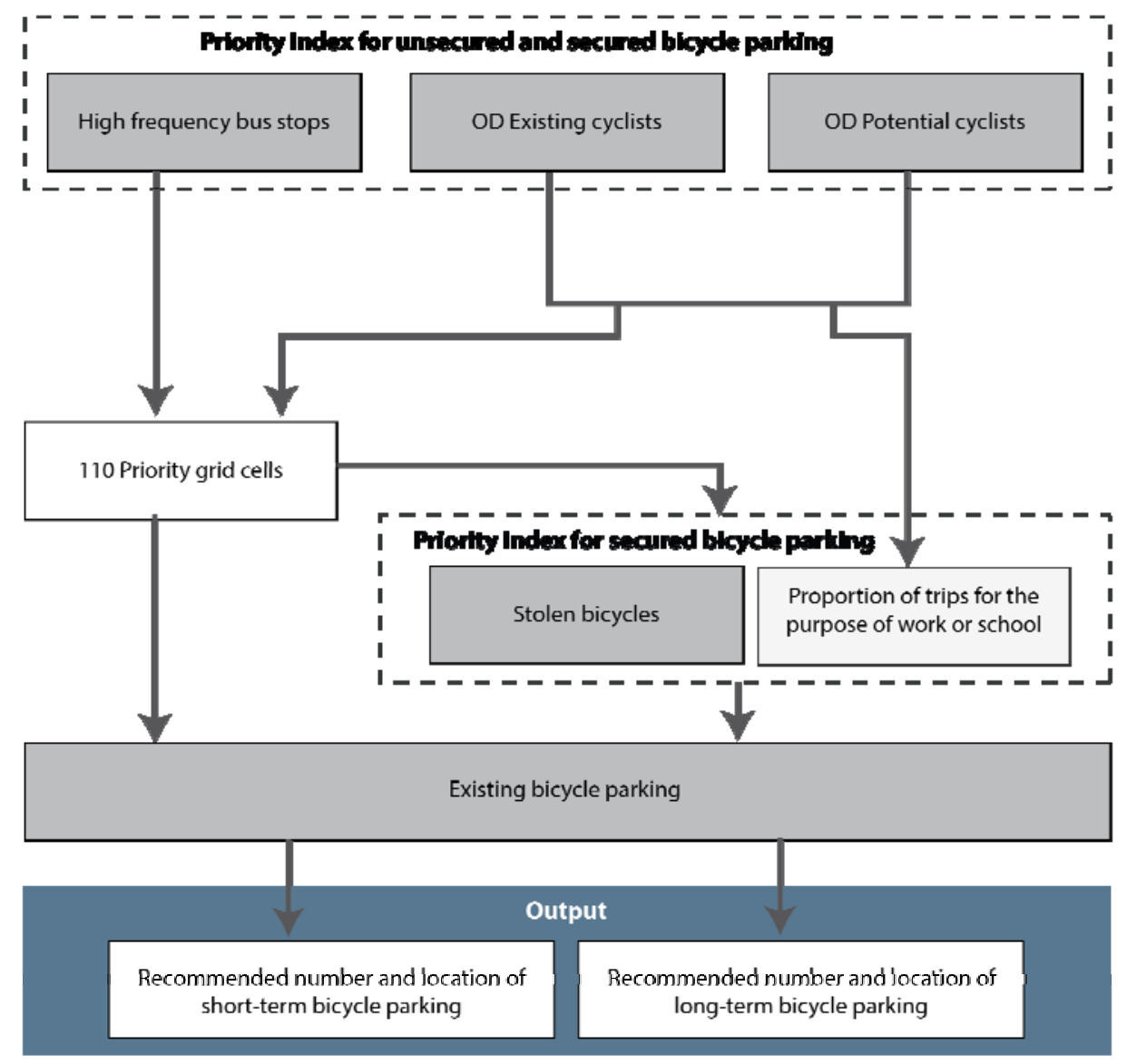

2 FIGURE 2 Flow chart of main steps in methodology.

\section{Data Sources}

4 The first data source used in our analysis is the 2011 Quebec Origin-Destination Survey 5 (OD), which collects information regarding trip purposes, modes, socio-demographic 6 characteristics and the origin and destination of each trip from respondents. OD Survey data 7 is collected every five years by phone and samples between 7 to $20 \%$ of all households 8 living in the city between September and December (24). The second source of data used is 9 the location of bus stops served by high-frequency bus routes called Metrobus. Metrobuses operate every 10 minutes during weekday peak hours. High frequency bus stops were used in this analysis, as Quebec City does not have a subway or light rail service. The data was extracted from the transit agency serving the City of Quebec's territory, called Réseau de Transport de la Capitale (RTC). The third and fourth data are the number of bicycle parking racks and spaces owned by the City of Quebec and the current bicycle network obtained from the City of Quebec. Our analysis only considered the number of public bicycle racks, since data on privately owned bicycle parking was unavailable. Due to data unavailability and because the City has a limited influence on the decision to add bicycle parking on university campuses, we excluded Laval University from our analysis, although it is a major cycling destination and requires its own specific analysis. The last data used in this analysis was the 2015 Bicycle Travel Survey conducted by the Transportation Research at McGill (TRAM) group. We extracted two questions from this survey. First, cyclists were asked if they had a bicycle stolen in the past, and if so, respondent ware asked to identify the location where it was stolen. 


\section{Prioritization Index for New Bicycle Parking}

2 Using the fishnet tool in ArcGIS, the first step was to generate a grid that covered the extent 3 of our study area, which was adapted from a previous study (5). The selected size of each 4 grid cell was 300 by 300 meters. This size was found optimal to aggregate multiple criteria, 5 such as the proximity of the bicycle network and the destinations of existing and potential 6 cyclists. The same grid cell size was employed by Larsen, Patterson and El-Geneidy (5), 7 however practitioners interested in reproducing our methodology can choose a grid cell size 8 that corresponds to their own city structure. We removed all cells that had their centroid 9 outside the boroughs of Quebec City and within Laval University Sainte-Foy campus, which

To identify and prioritize the best locations to install new bicycle parking, the first step consisted of generating a prioritization index. The index is composed of three indicators: 1) the destinations of existing cyclists, 2) the destinations of potential cyclists, and 3) the proximity to high frequency bus stops served by the Société de transport de la Capitale. The description of each indicator is presented below.

\section{Existing Cyclist's Destinations}

The first indicator used is the number of trips made by cyclists ending in each of the 5,185 grids. We used only home-based trips from the 2011 OD survey for all trip purposes. A total of 415 destinations were geocoded using x-y coordinates from the OD Survey. Next, we applied the expansion factor of each of these trips, to account for the expected magnitude of individuals in Quebec City making these trips. The expansion factor is described as a "sample weight" given to each trip according to their sample strata, and has the ability to adjust for potential bias introduced by the time and day that interviews took place or by underrepresented trips (24). After applying the expansion factor, a total of 5,918 trips made by cyclists were spatially joined to our working grid. Finally, we standardized the number of existing cyclists' trips ending in each grid cell with a Z-Score to enable the combination of this measure with others generated later in the study. The distribution of the destinations of existing cyclists is displayed in Figure 3A, which shows that their destinations are highly concentrated in downtown Quebec.

\section{Potential Cyclists' Destinations}

The second indicator is the number of potential cyclists ending their trip in each of the grid cells using the 2011 OD Survey. Within the context of our study, a potential cyclist trip is defined as a short-distance non-cycling trip which could be converted into a bicycle trip. Specifically, we used a threshold distance of 5.8 kilometers, which corresponds to the 75th percentile distance of all commuting bicycle trips evaluated from the OD 2011 survey. These short distance trips by bicycle would on average take 22 minutes at a pace of $16 \mathrm{~km} / \mathrm{h}(25)$. We calculated the trip length of these potential cyclists using a straight-line distance for simplicity between each origin and destination.

We adjusted the number of potential trips ending in each grid cell according to the expansion factor provided in the 2011 OD Survey. A total of 23,844 potential cyclist trips were extracted from the OD survey, which corresponds to 337,928 trips after applying the expansion factor. These trips were then spatially joined to the grid cells. Finally, we standardized the number of potential cyclists' trips ending in each grid cell with Z-Score. The results are shown in Figure 3B. Compared to the destinations of existing cyclists, the distribution of potential cyclists is more dispersed across the City of Quebec, however a similar high priority corridor in downtown Quebec is observed. 


\section{Number of Bus Stops}

The last indicator used in our priority index is the number of bus stops served by highfrequency bus routes, named Metrobus. We incorporated proximity to these bus stops to improve the integration of bicycling and public transit. Metrobus service consists of six highfrequency bus routes that are equipped with bicycle racks holding a maximum of two bicycles, and are the only bus routes operated by RTC equipped with bicycle racks (26). These bus routes are the most efficient public transit routes to reach the main employment and activity nodes in Quebec City. However, it is recommended to adapt our proposed method based on the local supply of public transit service, for example, by using subway stations instead of bus stops or using both high frequency bus routes and rail stations.

Using the RTC data, we identified 231 bus stops served by high-frequency bus routes. To avoid duplicating the number of bus stops, we only considered bus stops serving one direction. We then generated a buffer of 100 meters around each of them, and spatially joined these buffers with the grid cells, which enabled us to systematically sum the number of bus stop buffers intersecting each grid cell. The results were standardized using a Z-score and are shown in Figure 3C.

\section{Combining and Weighting Indicators into an Index}

We combined and weighted the three standardized indicators into one bicycle parking index. To arrive at our final index, we used a weighting scheme, where we applied a higher weighting to the destinations of existing cyclists, namely a weighting of 3 , and a weighting of 1.5 to potential cyclists. Whilst all three indicators are important, we decided to give more importance to existing cyclists' destinations to prioritize the current needs of bicycle parking. However, the application of a weighting scheme should vary according to a region's specific priorities or planning goals. The potential cyclists' trips are given a weight of 1.5 as we also wished to plan for potential needs of cyclists in a medium-term perspective. Finally, the number of bus stops was integrated without any weighting. The combined and weighted priority index result is displayed in Figure 3D.

After determining the priority areas for new bicycle parking, we identified grid cells falling within the top decile of the combined and weighted index, and selected which of these high priority areas are within 100 meters of the existing bicycle network. This resulted in 110 grid cells that are within proximity of a bicycle network. After locating these high priority areas for the installation of new bicycle parking, we first need to determine the recommended number of spaces that need to be installed in these grid cells, and second we consider where are the optimal locations to install new long-term bicycle parking within these grid cells. 

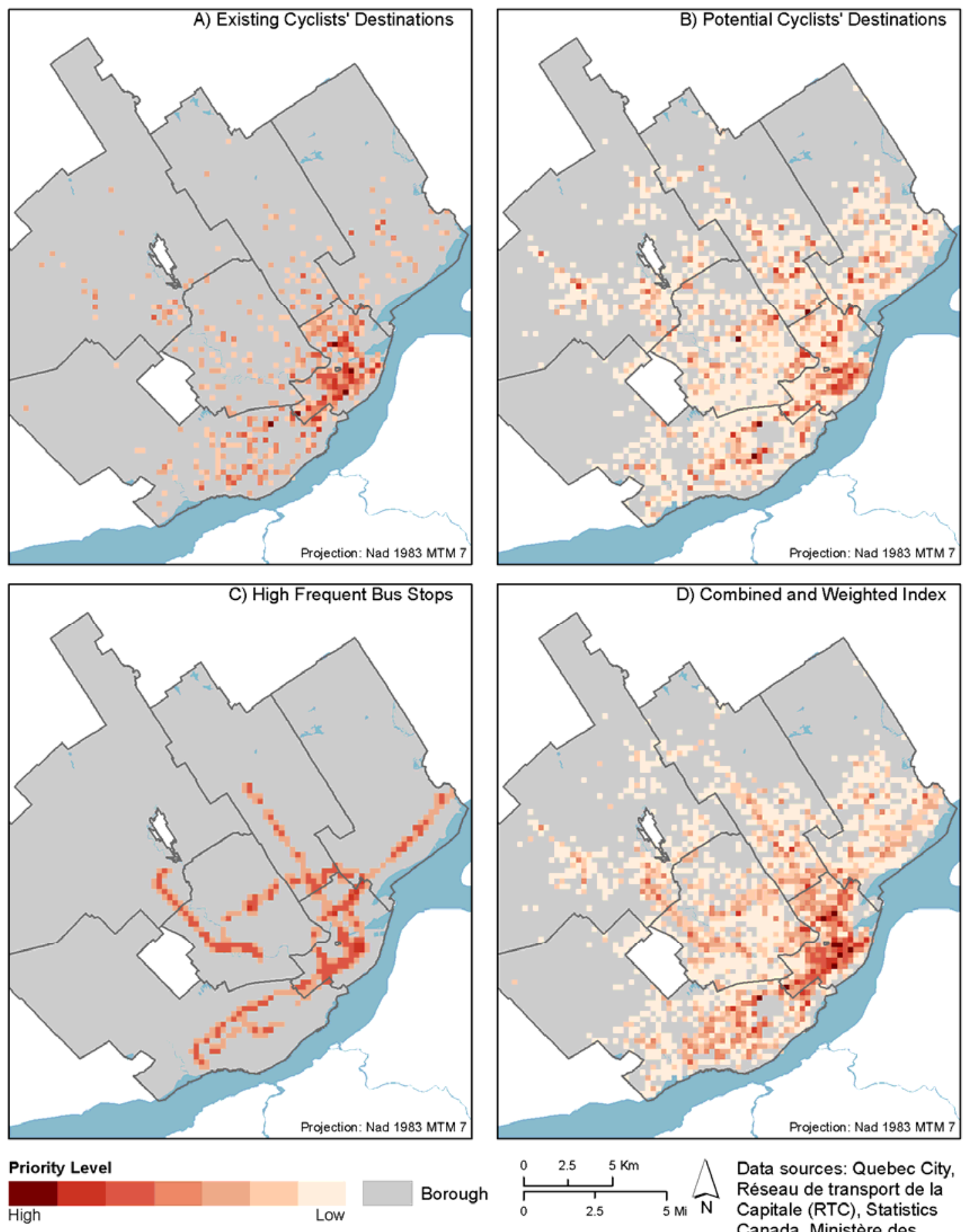

\section{FIGURE 3 Standardized indicators and Combined and Weighted Index.}

To estimate the number of bicycle spaces needed in these high priority grid cells, we summed the number of trips made by existing cyclists and $10 \%$ of the trips made by potential cyclists that end in each grid cell. Ten percent of potential trips assumes a moderate mode

6 shift from potential cyclists in the medium future. We then subtracted the bicycle parking 7 demand, identified in the above step, from the existing public parking spaces. Figure 4 8 presents the final 110 grid cells of high priority for bicycle parking and the recommended 
number of new bicycle parking spaces in each grid. These locations can be mainly short-term (bicycle racks), if a region wants to propose long-term bicycle parking more analysis is needed and this will be explained in the following section.
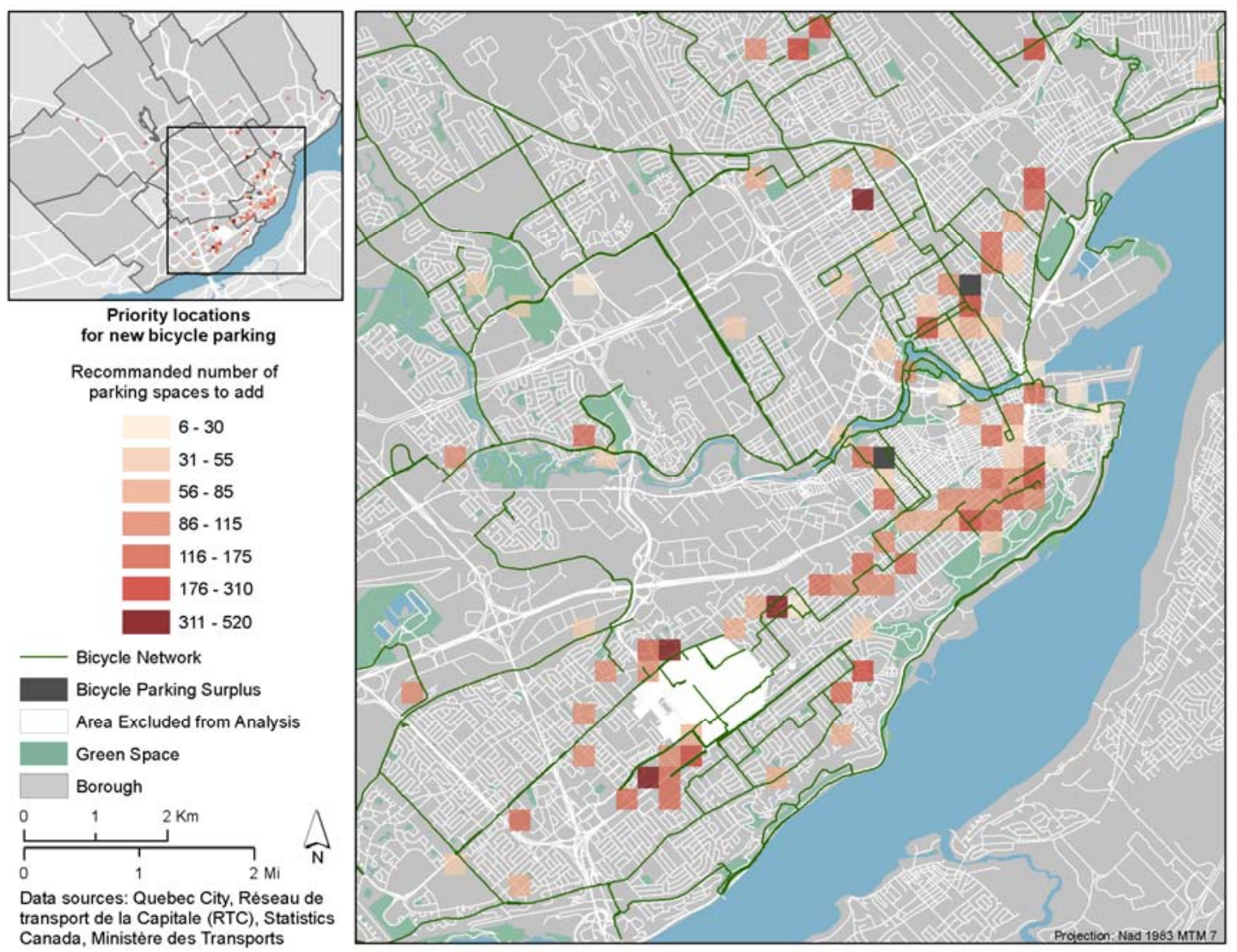

FIGURE 4 Priority locations to add new bicycle parking and recommended number of bicycle spaces to add.

\section{Long-term Bicycle Parking Index}

Using the high priority bicycle parking locations identified above (Figure 4), we next developed a priority index to determine the best locations to invest in long-term bicycle parking. The indicators considered for the prioritization of secured bicycle parking include the location of stolen bicycles and the proportion of existing and potential trips ending in each priority grid cells that are work or school trips (please refer to Figure 2 methodology overview).

Using the 2015 Bicycle Travel Survey conducted by the Transportation Research at McGill (TRAM) group, we geocoded the locations where respondents reported a stolen bicycle. We then spatially joined each location of a reported stolen bicycle to the 110 priority grid cells and summed the total number of bicycles stolen per grid cell. Finally, we standardized the number of stolen bicycles in each grid cell using a Z-Score. The results are shown in Figure 5A.

We then evaluated trips made by existing and potential cyclists for the purpose of commuting to work or school. Specifically, we calculated a ratio of trips to work or school compared to trips for all other purposes (i.e. shopping, grocery, health). Cyclists who commute to work or school require access to bicycle parking for a longer time, and the availability of long-term bicycle parking for this type of trip has been found to be an 
important determinant for cycling to work $(9 ; 13 ; 27 ; 28)$. Accordingly, we want to prioritize locations with higher ratios of work or school trips, as a strategy to encourage more individuals to cycle to work or school. We standardized the ratios of the high priority grid cells separately for existing and potential cyclists, and the results are shown in Figures 5B and 5C.

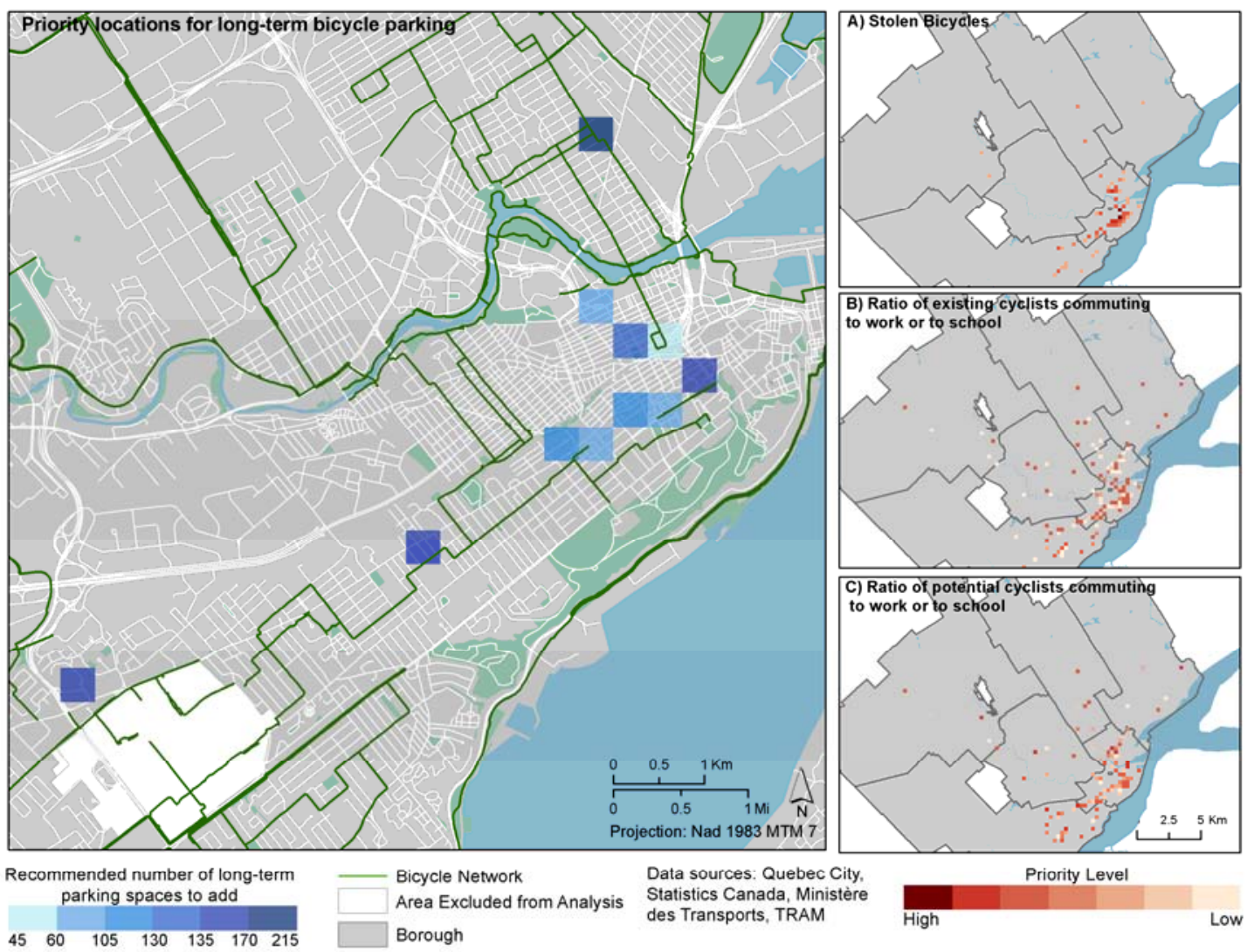

6

\section{Figure 5 Standardized indicators for the long-term bicycle parking index.}

\section{Combining and Weighting Indicators into an Index}

To generate our secured parking index, we combined and weighted the three standardized indicators. While all three indicators were selected because of their importance for planning for new long-term bicycle parking, we decided to give more weight to the number of stolen bicycles, knowing that the perceived risk of bicycle theft can discourage individuals from using their bicycle $(9 ; 10)$. Accordingly, a weighting of 3 was attributed to this indicator. The ratio of existing cyclists commuting to work or school was assigned a weight of 2 and the ratio of potential cyclists commuting to work or school was assigned a weight of 1.5. With such criteria, we prioritize locations for investments in long-term bicycle parking in areas where we know there are cyclists currently commuting, however the weighting attributed to potential cyclists was not considerably lower, since we would hope that access to secure bicycle parking would lead to a major mode shift towards cycling.

The cells falling in the top decile of the combined and weighted index were identified as priority locations for investment in long-term bicycle parking. To recommend the number of secured bicycle spaces in each cell, we calculated the optimal number of spaces using the same method as the short-term bicycle parking. We calculated the difference between the number of existing bicycle parking spaces and the current and potential cycling demand in each grid cell, where we estimated the demand to be the number of existing cyclists whose 
trip ends in each grid cell plus $10 \%$ of all potential cyclists whose trips end in each grid cell. The recommended locations and number of long-term bicycle parking spaces to be installed are displayed in Figure 5. It is important to note that this step can be adjusted if there is an existing supply of long-term bicycle parking in a region.

\section{DISCUSSION AND CONCLUSION}

The objective of this paper was to develop a practice ready GIS-based method to identify optimal locations to add both short-term and long-term bicycle parking, which aims to be flexible and easily adaptable to different contexts. Using the City of Quebec as a case study, we first divided the city into 300 by 300 meter grid cells. The use of grid cells is recommended in this kind of analysis as it guides planners to areas according to needs, providing them with latitude to closely evaluate this zone and find the appropriate location based on the existing land use. This work must be followed by more detailed analysis to locate bicycle parking spaces within the identified grid cells, which requires more local knowledge that can only be present among local planning authorities. We generated the prioritization index for new bicycle parking according to what factors were identified as likely to contribute to the need for new long-term or short-term parking, namely the destinations of existing and potential cyclists and proximity to high frequency transit service. While we did not consider linked trips of existing and potential cyclists, practitioners and researchers could include them to tailor our method according to their needs. These indicators were then combined and a weighting scheme was applied, which is recommended to be devised according to the objectives or local planning goals and priorities of a region. Finally, we only selected grid cells within 100 meters of the existing bicycle network, to prioritize locations that contribute the most to the development of a complete cycling network and to ensure high usage levels of these newly proposed facilities. The recommended number of parking spaces for each grid cell was then calculated according to the existing supply of parking and the existing and potential demand for bicycle parking. For the recommended priority locations of long-term bicycle parking, we developed a priority index which considered the location of stolen bicycles and grid cells with high proportions of existing and potential cyclists commuting into each grid cell. The number and the type of indicators utilized could be tailored to other regions according to data availability and policy goals. Moreover, the weighting scheme applied to each indicator could also be modified according to different contexts and local planning goals and priorities.

The strength of our method lies in its flexibility and ability to account for long-term demand for bicycle parking as we specifically consider work and school trip purposes, as access to these secured bicycle facilities have been shown to encourage cyclists to commute to their workplace or school $(10 ; 13 ; 28)$. Long-term bicycle parking is expected to be an integral part of the improvement of Quebec City's bicycle network, and is expected to help Quebec reach its goal of providing residents with a safe and connected bicycle network to attract and encourage cycling for everyday purposes, such as commuting.

It is important to note that our methodology to locate long-term bicycle parking, proceeded under the assumption that such facilities will be provided for free to users. As many regions provide these facilities to users for a fee, demand will need to be adjusted according to the willingness of cyclists to pay for access to this service. Knowledge of cyclists' willingness to pay for long-term bicycle parking can be the subject of a future study.

\section{ACKNOWLEDGEMENTS}

This study was made possible with the collaboration of Mr. Jean-François Martel, 
1 transportation planner at the City of Quebec, who provided the municipal bicycle parking 2 data. We would also like to thank Genevieve Boisjoly for her helpful inputs. This study was 3 funded by the Social Sciences and Humanities Research Council of Canada and the Natural 4 Sciences and Engineering Research Council of Canada. 


\section{REFERENCES}

[1] Pucher, J., J. Dill, and S. Handy. Infrastructure, programs, and policies to increase bicycling: An international review. Preventive Medicine, Vol. 50, 2010, pp. S106-S125. [2] Pucher, J., and R. Buehler. Making Cycling Irresistible: Lessons from The Netherlands, Denmark and Germany. Transport Reviews, Vol. 28, No. 4, 2008, pp. 495-528.

[3] Dill, J., and T. Carr. Bicycle commuting and facilities in major U.S. cities. If You build them, commuters will use them. Transportation Research Record, No. 1828, 2003, pp. 116123.

[4] Buelhler, R., and J. Pucher. Cycling to work in 90 large American cities: New evidence on the role of bike paths and lanes. Transportation, Vol. 39, 2011, pp. 409-432.

[5] Larsen, J., Z. Patterson, and A. El-Geneidy. Build it. But where? The use of geographic information systems in identifying locations for new cycling infrastructure. International Journal of Sustainable Transportation, Vol. 7, No. 4, 2013, pp. 299-317.

[6] Buehler, R. Determinants of bicycle commuting in the Washington, DC region: The role of bicycle parking, cyclist showers, and free car parking at work. Transportation Research Part D, Vol. 17, 2012, pp. 525-531.

[7] Wardman, M., M. Tight, and M. Page. Factors influencing the propensity to cycle to work. Transportation Research Part A, Vol. 41, 2007, pp. 339-350.

[8] Pucher, J., R. Buehler, and M. Seinen. Bicycling renaissance in North America? An update and re-appraisal of cycling trends and policies. Transportation Research Part A, Vol. 45, 2011, pp. 451-475.

[9] Rietveld, P., and V. Daniel. Determinants of bicycle use: do municipal policies matter? Transportation Research Part A, Vol. 38, 2004, pp. 531-550.

[10] Rietveld, P. The accessibility of railway Stations: The role of the bicycle in The Netherlands. Transportation Research Part D, Vol. 5, 2000, pp. 71-75.

[11] van Lierop, D., M. Grimsrud, and A. El-Geneidy. Breaking into bicycle theft: Insights from Montreal, Canada. International Journal of Sustainable Transportation, Vol. 9, No. 7, 2015, pp. 490-501.

[12] Gamman, L., A. Thorpe, and M. Willcocks. Bike Off! Tracking the design terrains of cycle parking: reviewing use, misuse and abuse. Crime Prevention and Community Safety: An international Journal, Vol. 6, No. 4, 2004, pp. 19-36.

[13] Hunt, J. D., and J. E. Abraham. Influences on bicycle use. Transportation, Vol. 34, 2007, pp. 453-470.

[14] Martens, K. Promoting bike-and-ride: The Dutch experience. Transportation Research Part A, Vol. 41, 2007, pp. 326-338.

[15] Van der Spek, S., and N. Scheltema. The importance of bicycle parking management. Research in Transportation Business \& Management, Vol. 15, 2015, pp. 39-49.

[16] Krizek, K., and E. Stonebraker. Bicycle and Transit: A Marriage Unrealized. Transportation Research Record, No. 2144, 2010, pp. 161-167.

[17] Bachand-Marleau, J., J. Larsen, and A. El-Geneidy. Much-Anticipated Marriage of Cycling and Transit. How Will It Work? Transportation Research Record, No. 2247, 2011, pp. 109-117.

[18] Rybarczyk, G., and C. Wu. Bicycle facility planning using GIS and multi-criteria decision analysis. Applied Geography, Vol. 30, 2010, pp. 282-293.

[19] García-Palomares, J. C., J. Gutiérrez, and M. Latorre. Optimizing the location of stations in bike-sharing programs: A GIS Approach. Applied Geography, Vol. 35, 2012, pp. 235-346. [20] Statistics Canada. Census Profile, 2016 Census, Québec, Ville [Census Subdivision]. Statistics Canada. http://www12.statcan.gc.ca/census-recensement/2016/dp- 
$1 \mathrm{pd} / \mathrm{prof} /$ details/page.cfm?Lang=E\&Geo1=CSD\&Code $1=2423027 \& \mathrm{Geo} 2=\mathrm{PR} \&$ Code $2=01 \& \mathrm{D}$

2 ata $=$ Count $\&$ SearchText $=$ Quebec $\&$ SearchType $=$ Begins $\&$ SearchPR $=01 \& T A B I D=1 \& B 1=A 11$.

3 [21] Vincens, M., M. Vandersmissen, and M. Thériault. Impacts de la restructuration du

4 réseau d'autobus de la ville de Québec sur l'accessibilité aux emplois des femmes et sur la

5 mobilité professionelle. Cahiers de géographie du Québec, Vol. 51, No. 144, 2007, pp. 419-

6446.

7 [22] Ville de Québec. Vision des déplacements à vélo, 2016.

8 [23] ---. Bilan vélo 2016. Détail des projets 2016 et des comptages, 2017.

9 [24] Ministère des Transports du Québec. Enquête Origine-Destination 2011. La mobilité des

10 personnes dans la région de Québec. Volet Enquête-ménages. Sommaire des résultats, 2015.

11 [25] El-Geneidy, A., K. Krizek, and M. Iacono. Predicting bicycle travel speeds along

12 different facilities using GPS data: A proof of concept model.In Paper presented at the

Proceedings of the 86th Annual Meeting of the Transportation Research Board, Compendium of Papers., 2007.

[26] Réseau de transport de la Capitale (RTC). À chacun son bus. Trouvez le service qui convient à vos besoins! https://www.rtcquebec.ca/Default.aspx?tabid=104\&language=fr-CA. [27] Yan, K., and J. Zheng. Study of Bicycle Parking in Central Business District of Shanghai. Transportation Research Record, No. 1441, 1994, pp. 27-35. 